\title{
Elemental Profiling and Identification of Eco-Toxic Elements in Agricultural Soil by Laser-Induced Breakdown Spectroscopy
}

\author{
Abul F.M.Y. Hai der ${ }^{*}$, Fir oza Kabir, M. Hedayet Ullah, Z.H. Khan, Kazi M. Abedin \\ Department of Phy sics, University of Dhaka, Dhaka, Bangladesh \\ *Corresponding author: yuhaider@univdhaka.edu
}

Received May 15, 2013; Revised May 22, 2013; Accepted May 23, 2013

\begin{abstract}
Laser induced breakdown spectroscopy (LIBS) was used to determine the elemental content and to detect probable eco-toxic elements in agricultural soil in Gazipur, Bangladesh (latitude: $24.0958^{\circ} \mathrm{N}$, longitude: $90.4125^{\circ}$ E). Soil samples were collected from three experimental plots of Bangladesh Rice Research Institute (BRRI), Gazipur and from a fallow land in the same area where no crop has been produced for a long time. This land is believed to be contaminated by the affluent discharged from nearby industries. Rice and husk samples were also collected from one of the experimental plots. Several elements such as $\mathbf{N i}, \mathbf{C u}, \mathbf{Z n}, \mathbf{F e}, \mathbf{C a}, \mathbf{A l}, \mathbf{S i}, \mathbf{S n}, \mathbf{N a}, \mathbf{K}$, Ti, Mn, Li, Mo, Co were identified in the soil samples of the three experimental plots. Rice and husk samples also have the same elements including Sr, P, C and Mg. The LIBS study of the soil of the fallow land confirms the presence of the toxic ele ment $\mathrm{Cd}$ along with all the ele ments found in the soil samples of the experimental plots. The sample from the fallow land from Gazipur was also analyzed for $\mathrm{Cd}$ by atomic absorption spectroscopy (AAS). The presence of $6.5 \mathrm{ppm}$ of $\mathrm{Cd}$ in this fallow land above the tolerance limit ( $3 \mathrm{ppm})$ is supposedly the main reason for barrenness of the fallow land in the present case.
\end{abstract}

Keywords: LIBS, cadmium, eco-toxic, barrenness, AAS

\section{Introduction}

LIBS has been established as a fast spectroscopic technique for multi-elemental detection of elements in many diverse situations $[1,2,3]$. In this technique a high power laser pulse is used for the generation of weakly ionized plas ma from the samples. The spectral emission lines from the excited atoms/ions of the plasma are then spectroscopically analyzed for both qualitative and quantitative detection of multiple elements in the sample. The technique is extremely versatile and powerful, and is capable of analyzing solid, liquid and gaseous samples. For example, LIBS has been used for the detection of trace elements of soils [4,5], geological analysis [6], aerosol analysis [7,8], analyses of industrial waste water $[9,10]$ etc, to name a few.

In this paper, we used LIBS technique for the analysis of agricultural soil in Gazipur in Bangladesh (latitude: $24.0958^{\circ} \mathrm{N}$, longitude: $90.4125^{\circ} \mathrm{E}$ ) with a view to detect potentially harmful elements and to determine whether they (the toxic elements) get into our food chain through rice and husk.

\section{Experimental Details}

In the present LIBS experiment intense, transient plasma was produced by focusing the fundamental beam at $1064 \mathrm{~nm}$ from a Q-switched Nd: YAG laser (SpectraPhysics LAB-170-10) on the sample by a convex lens of $100 \mathrm{~mm}$ focal length. The laser pulse had a temporal width of $8 \mathrm{nsec}$ and repetition rate of $10 \mathrm{~Hz}$. The beam has a Gaussian profile in the far-field and has a beam divergence of less than $0.5 \mathrm{~m}$ rad. The experiments were performed in air. The laser pulse energy used was $40 \mathrm{~mJ}$. The spot size at the sample position was about $200 \mu \mathrm{m}$. The light emitted from the plasma was focused by a fused quartz lens $(\mathrm{f}=50 \mathrm{~mm})$ and collected by a $3 \mathrm{~m}$ long multimode silica optical fiber and was then transmitted through the fiber to the entrance slit of a $750 \mathrm{~mm}$ focal length computerized Czerny-Turner spectrograph (Acton Model SP-2758). The spectrograph was equipped with three ruled gratings: 2400, 600 and 300 grooves $/ \mathrm{mm}$ blazed at 240, 500 and $300 \mathrm{~nm}$, respectively, which were interchangeable under computer control. The schematic diagram of the experimental set up and more details are available els ewhere [11].

The spectrum was detected by an intensified and gated CCD camera (Unigen II coated Princeton PI-MAX camera with $1024 \mathrm{X} 1024$ pixels). The ICCD camera was electrically triggered by the Nd: YAG laser pulse after a software-controlled, adjustable time delay. In this way, the intense background initially created by the hightemperature plasma was largely eliminated, and the atomic/ionic emission lines of the elements were more clearly observed. In the present experiments, a delay time $\mathrm{t}_{\mathrm{d}}$ of $1.5 \mu \mathrm{s}$ and a gate width $\mathrm{t}_{\mathrm{w}}$ of $50 \mu \mathrm{s}$ were selected for the optimum signal. Usually, spectra from a number of 
laser shots (about 40-80) were acquired and averaged to increase the signal-to-noise ratio. Samples were manually moved between exposures to prevent crater formation and to avoid other deleterious effects. The spectrum, captured by the ICCD camera, was transferred to the personal computer by USB cable. All the functions of the ICCD camera and the Acton spectrograph were fully controlled by the WinSpec/32 software provided by the manufacturer [12].

\subsection{Sample Processing}

Soil samples from three experimental plots of Bangladesh Rice Research Institute (BRRI), Gazipur, were collected with crop yield records. Varieties of fertilizers were used in different plots. The fertilizers that were applied to the fields were NPK (Nitrogen, Phosphorous Potassium), NPKSZn (Nitrogen, Phosphorous, Potassium, Sulphur, zinc) and NPKSZnCu (Nitrogen, Phosphorous, Potassium, Sulphur, Zinc, and Copper). Again samples were collected from a fallow land (of Gazipur), where no crop is produced for a long time. This land is believed to be contaminated by the affluent discharged from nearby industries (textile and paint industry). Rice and husk samples were also collected from the land where NPK fertilizer was applied.
The collected samples were powdered by hand mortar and pestle. Then the powder of each sample was passed separately through a 75 micron sieving machine which makes the sample most homogeneous to carry out LIBS experiment. Small pellets were made by using a hand press with sufficient pressure (80 bars).

\section{Results and Discussions}

For every sample spectra we re acquired in the UV to IR region (190 to $900 \mathrm{~nm})$ using two gratings. A 600 grooves $/ \mathrm{mm}$ grating blazed at $500 \mathrm{~nm}$ was used to take spectra in the range of $360-880 \mathrm{~nm}$. Another grating of $2400 \mathrm{~g} / \mathrm{mm}$ blazed at $240 \mathrm{~nm}$ was used for $190-360 \mathrm{~nm}$ spectral range.

Some representative LIBS spectra for the soil sample NPK are shown in the Figure 1(a) and Figure 2(a) where different emission lines are labeled with the charge state of the ele ments. The standard database of atomic emission lines of the US National Institute of Standard and Technology [13] was used for the identification of the elements from the observed spectrum [14]. Table 1 summarizes the elements detected in different soil samples including rice and husk samples from the experimental plot NPK.

Table 1. Elements found in diffe rent soil samples including rice and husk. A tick indicates the presence of the element in the sample whereas a cross indicates the absence of the element in the sample

\begin{tabular}{|c|c|c|c|c|c|c|}
\hline Elements & NPK & NPKSZn & NPKSZnCu & $\begin{array}{c}\text { Fallow land } \\
\text { (Gazipur) }\end{array}$ & Rice & Husk \\
\hline $\mathrm{Fe}$ & $\sqrt{ }$ & $\sqrt{ }$ & $\sqrt{ }$ & $\sqrt{ }$ & $\sqrt{ }$ & $\sqrt{ }$ \\
\hline $\mathrm{Cu}$ & $\sqrt{ }$ & $\sqrt{ }$ & $\sqrt{ }$ & $\sqrt{ }$ & $\sqrt{ }$ & $\sqrt{ }$ \\
\hline $\mathrm{Na}$ & $\sqrt{ }$ & $\sqrt{ }$ & $\sqrt{ }$ & $\sqrt{ }$ & $\sqrt{ }$ & $\sqrt{ }$ \\
\hline $\mathrm{Ca}$ & $\sqrt{ }$ & $\sqrt{ }$ & $\sqrt{ }$ & $\sqrt{ }$ & $\sqrt{ }$ & $\sqrt{ }$ \\
\hline $\mathrm{Ti}$ & $\sqrt{ }$ & $\sqrt{ }$ & $\sqrt{ }$ & $\sqrt{ }$ & $\sqrt{ }$ & $\sqrt{ }$ \\
\hline $\mathrm{Si}$ & $\sqrt{ }$ & $\sqrt{ }$ & $\sqrt{ }$ & $\sqrt{ }$ & $\sqrt{ }$ & $\sqrt{ }$ \\
\hline $\mathrm{Co}$ & $\sqrt{ }$ & $\sqrt{ }$ & $\sqrt{ }$ & $\sqrt{ }$ & $\sqrt{ }$ & $\sqrt{ }$ \\
\hline $\mathrm{Ni}$ & $\sqrt{ }$ & $\sqrt{ }$ & $\sqrt{ }$ & $\sqrt{ }$ & $\sqrt{ }$ & $\sqrt{ }$ \\
\hline $\mathrm{Al}$ & $\sqrt{ }$ & $\sqrt{ }$ & $\sqrt{ }$ & $\sqrt{ }$ & $\sqrt{ }$ & $\sqrt{ }$ \\
\hline $\mathrm{Zn}$ & $\sqrt{ }$ & $\sqrt{ }$ & $\sqrt{ }$ & $\sqrt{ }$ & $\sqrt{ }$ & $\sqrt{ }$ \\
\hline $\mathrm{Li}$ & $\sqrt{ }$ & $\sqrt{ }$ & $\sqrt{ }$ & $\sqrt{ }$ & $\sqrt{ }$ & $\sqrt{ }$ \\
\hline $\mathrm{K}$ & $\sqrt{ }$ & $\sqrt{ }$ & $\sqrt{ }$ & $\sqrt{ }$ & $\sqrt{ }$ & $\sqrt{ }$ \\
\hline $\mathrm{Cd}$ & $x$ & $x$ & $x$ & $\sqrt{ }$ & $x$ & $x$ \\
\hline $\mathrm{Sn}$ & $\sqrt{ }$ & $\sqrt{ }$ & $\sqrt{ }$ & $\sqrt{ }$ & $\sqrt{ }$ & $\sqrt{ }$ \\
\hline $\mathrm{Mn}$ & $\sqrt{ }$ & $\sqrt{ }$ & $\sqrt{ }$ & $\sqrt{ }$ & $\sqrt{ }$ & $\sqrt{ }$ \\
\hline $\mathrm{Sr}$ & $x$ & $x$ & $x$ & $x$ & $\sqrt{ }$ & $\sqrt{ }$ \\
\hline Mo & $\sqrt{ }$ & $\sqrt{ }$ & $\sqrt{ }$ & $\sqrt{ }$ & $\sqrt{ }$ & $\sqrt{ }$ \\
\hline $\mathrm{P}$ & $x$ & $x$ & $x$ & $x$ & $\sqrt{ }$ & $\sqrt{ }$ \\
\hline $\mathrm{C}$ & $x$ & $x$ & $x$ & $x$ & $\sqrt{ }$ & $\sqrt{ }$ \\
\hline $\mathrm{Mg}$ & $x$ & $x$ & $x$ & $x$ & $\sqrt{ }$ & $\sqrt{ }$ \\
\hline
\end{tabular}

The LIBS spectrum for the soil samples of the fallow land in Gazipur are shown in Figure 1(b) and Figure 2(b) and the different emission lines are labeled with the charge state of the elements. In the LIBS spectra of the fallow land, we identified five (three of them shown in Figure 1(b) and Figure 2(b)) unambiguous lines of $\mathrm{Cd}$ which conclusively proves the existence of $\mathrm{Cd}$ in the soil sample of the fallow land. No other heavy/toxic metal could be detected in this soil sample.

The concentration of $\mathrm{Cd}$ in the fallow land was determined by AAS. In this technique, for digestion, powdered soil samples approximately $0.5 \mathrm{gm}$ was taken in digestion vessel. Then $10 \mathrm{ml}$ concentrated $\mathrm{HNO}_{3}(65 \%$ annular grade) was added and the sample was micro-wave digested for 30 minutes at $115^{\circ} \mathrm{C}$. After digestion, the sample was transferred in a $25 \mathrm{ml}$ volumetric flask and made up to mark with de-ionized water and then filtered. Dilution of the sample was done by de-ionized water. Cadmium (228.8nm) specific hollow cathode lamp was used for this purpose.

The concentration of $\mathrm{Cd}$ in the soil sample of the fallow land was determined to be $6.5 \mathrm{ppm}$ by the ASS technique.

From the consolidated Table 1, it is found that the elements Ni, Cu, Zn, Fe, Ca, Al, Si, Sn, Na, K, Ti, Mn, $\mathbf{L i}, \mathbf{M o}, \mathbf{C o}$ are present in all the soil samples of the experimental plots (NPK, NPKSZn, NPKSZn). Michael 
E. Essington et al. [15] found the elements $\mathrm{Al}, \mathrm{Ca}, \mathrm{Fe}$, and $\mathrm{Mg}, \mathrm{Ti}, \mathrm{Ba}, \mathrm{Na}, \mathrm{Cu}$, and $\mathrm{Mn}$ by LIBS but they could not detect the emis sion lines of $\mathrm{Cr}, \mathrm{Ni}$, and $\mathrm{Zn}, \mathrm{P}$ and $\mathrm{K}$ in soil

\section{NPKsoil sample}

(Cdisabsent)

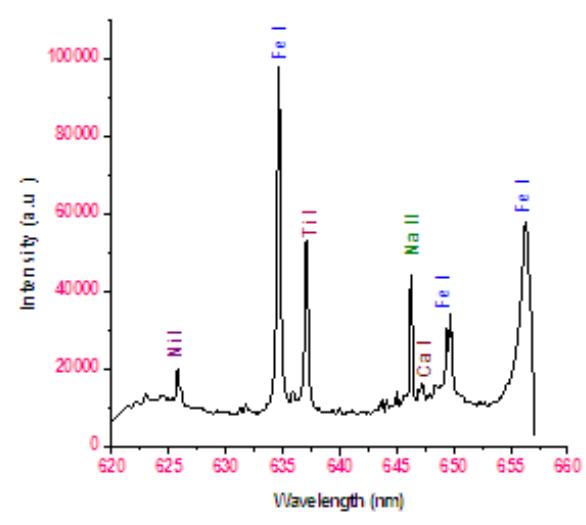

Figure 1(a) samples. We have found $\mathrm{Ni}, \mathrm{Zn}$ and $\mathrm{K}$ because of the greater sensitivity of our intensified and gated CCD detector.

\section{Soil sample of fallow land (Cdispresent)}

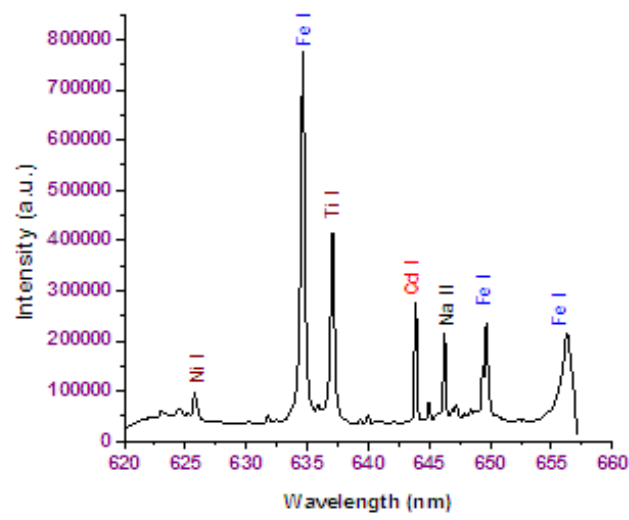

Figure 1(b)

Figure 1. The LIBS spectra of NPK soil sample (a) and of fallow land soil sample (b) in the spectral range of $620 \mathrm{~nm}$ to $657 \mathrm{~nm}$
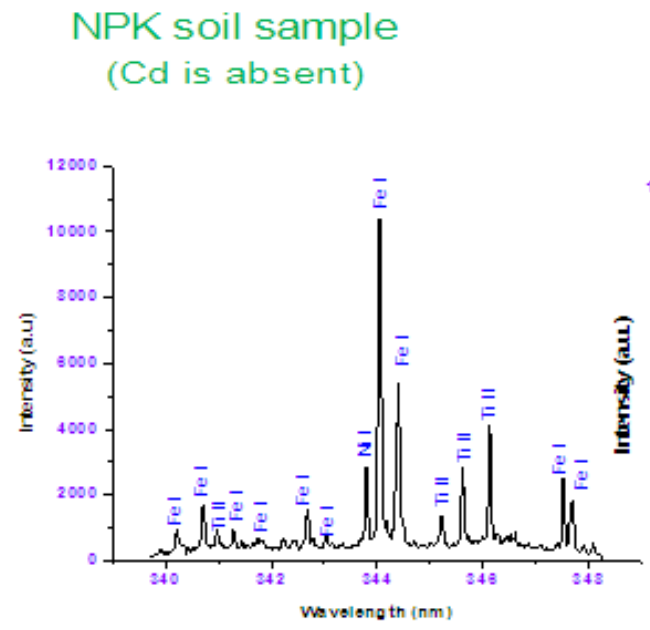

Figure 2(a)
Soil sam ple of fallow land

(Cd is present)

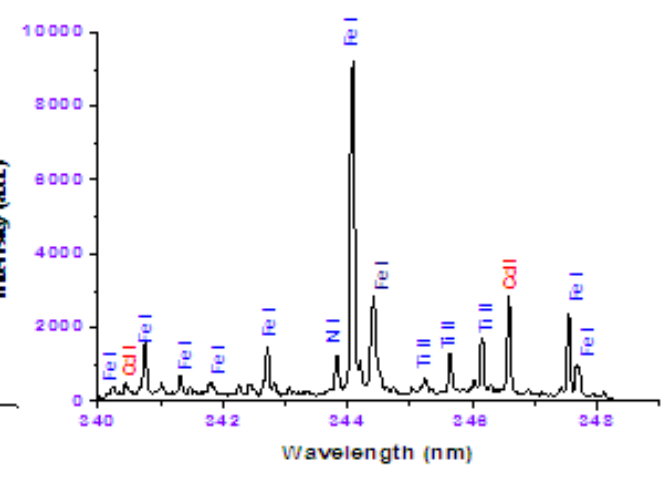

Figure 2(b)

Figure 2. The LIBS spectra of NPK soil sample (a) and of fallow land soil sample (b) in the spectral range of $340 \mathrm{~nm}$ to $348 \mathrm{~nm}$

Rice and husk samples also showed the presence of the same elements as those found in experimental soil samples in addition to $\mathrm{Sr}, \mathrm{P}, \mathrm{C}$ and $\mathrm{Mg}$ (Table 1). The elements except carbon enter into our food chain through rice from the soil. Carbon from atmosphere gets into our food system through photosynthesis in the leaves of the paddy plants. The concentrations of $\mathrm{P}, \mathrm{Sr}$ and $\mathrm{Mg}$ in soil samples are perhaps below the detection limit of the present LIBS set up while the concentrations of these elements in rice and husk are high enough (due to their selective absorption by the paddy plants from the soil) to be detected by the present LIBS set up. The soil sample of the fallow land has the same elements which were found in the soil samples of the experimental plots in addition to the toxic element $\mathrm{Cd}$. None of the experimental plots with significant crop yield contains toxic elements like $\mathrm{Cd}, \mathrm{Cr}$, $\mathrm{Hg}, \mathrm{Pb}$ nor does the rice and husk samples. So there is no alarm for these toxic elements to get into the food chain of the people/domestic animals that uses the rice/husk from Gazipur.

This experiment has detected the presence of micronutrients (such as $\mathrm{Ni}, \mathrm{Cu}, \mathrm{Zn}, \mathrm{Fe}, \mathrm{Mn}, \mathrm{Na}$ ) as well as some macro-nutrients (such as $\mathrm{Ca}, \mathrm{K}, \mathrm{Si}$ ) in all the experimental plots irrespective of the fertilizers given to the different plots. The addition of different fertilizers has increased the amount of these micro-macro nutrients in the soils. However no quantitative determination of these nutrients was attempted in the present study. These 
elements are essential for plants [16]. The study of the soil samples of the fallow land reveals the presence of toxic element $\mathbf{C d}$ at a concentration of $6.5 \mathrm{ppm}$ (which is above the tolerance limit) along with all the elements found in the soil samples of the experimental plots. The maximum tolerance limit of $\mathrm{Cd}$ for soil is $3 \mathrm{ppm}[17,18]$.

\section{Conclusion}

The present LIBS technique has been applied to get an elemental profile of the soil samples of agricultural lands. Cadmium coming from the affluent discharged from nearby industries is responsible for turning the previously fertile agricultural land into a fallow land. The elemental contents of rice and husk indicate that most of the elements present in the soil get into our food chain through the rice we consume. Since no toxic elements were identified in rice and husk, there is no risk of any toxic element getting into our food chain.

$\mathrm{Cd}$ was found only in the fallow land. No Cd was found in any experimental plots with satisfactory crop yields. $\mathrm{Cd}$ has deleterious effect on plant whose presence in the soil inhibits significant plant growth in the soil. This is consistent with the known adverse effects of $\mathrm{Cd}$ on plant growth in general [19]. The presence of $\mathrm{Cd}$ in the fallow land is responsible for this land to be barren. Any chemical treatment of this fallow land which can remove the $\mathrm{Cd}$, can make the fallow land productive again, since other toxic elements like $\mathrm{Cr}, \mathrm{Hg}, \mathrm{Pb}$ were not found in the fallow land.

\section{Acknowledgements}

The experiments were performed at the Center for Advance Research in Sciences, University of Dhaka. The research was partially funded through awarding scholarship (to Firoja Begum) under AIF/HEQEP/UGC/World Bank sub-project titled 'Monitoring of Surface Pollution and Atmospheric Condition in Bangladesh by Laser-based technique (CP240)'.

\section{References}

[1] Cremers DA, Radziemski RJ. 2006. Handbook of Laser-Induced Breakdown Spectroscopy. New York: John Wiley.
[2] Miziolek AW, Palleschi V, Schechter I. 2006. Laser-Induced Breakdown Spectroscopy (LIBS): Fundamentals and Applications. Cambridge: Cambridge University Press.

[3] Singh JP, Thakur SN. (Editors). 2007. Laser-Induced Breakdown Spectroscopy. Elsevier.

[4] Martin MZ, Wullschleger SD, Garten CT Jr. Palumbo AV. 2003. Laser-induced breakdown spectroscopy for the environmental determination of total carbon and nitrogen in soils. Appl. Opt., 42, 2072.

[5] Arca G., Ciucci A., Palleschi V., Rastelli S. and Tognoni E. 1996. Appl. Phys. B 63. 185. Barker AV, Pilbeam DJ. Handbook of Plant Nutrition. 2007, CRC Press.

[6] Harmon RS, Delucia FC, Mcmanus CE. Mcmillan NJ. Jenkins TF, Walsh ME, Miziolek A W. 2006. Laser-induced breakdown spectroscopy - An emerging chemical sensor technology for realtime field-portable, geochemical, mineralogical, and environmental applications. Appl. Geochem. 21. 730.

[7] Samuels AC, Delucia FC Jr., Mcnesby KL, Miziolek AW. 2003. Laser-Induced Breakdown Spectroscopy of Bacterial Spores, Molds, Pollens, and Protein: Initial Studies of Discrimination Potential. Appl. Opt. 42. 6205.

[8] Radziemski LJ, Loree TR, Cremers DA, Hoffman NM. 1983. Time-resolved laser-induced breakdown spectrometry of aerosols. Anal. Chem. 55. 1246.

[9] Rai NK and Rai AK. 2008. LIBS - An efficient approach for the determination of $\mathrm{Cr}$ in industrial Wastewater. J. Hazardous Materials. 150. 835.

[10] Gondal M.A., Hussain T. 2007. Determination of poisonous metals in wastewater collected from paint manufacturing plant using laser-induced breakdown spectroscopy. Talanta.71.73.

[11] Haider A.F.M.Y., Rony M.A., Lubna R.S. and Abedin K.M. 2011 Detection of multiple elements in coal samples from Bangladesh by Laser-induced Breakdown Spectroscopy.Optics and Laser Technology, 43. 1405.

[12] Haider A.F.M.Y., Lubna R.S. and Abedin K.M. 2012. Elemental Analyses and Determination of Lead Content in Kohl (Stone) by Laser-Induced Breakdown Spectroscopy. Applied Spectroscopy. 66(4). 420.

[13] http://physics.nist.gov/PhysRefData/ASD/lines_form.html.

[14] Abedin, K.M., Haider, A.F.M.Y., Rony, M.A. and Khan, Z.H., 2011. Identification of multiple rare earths and associated elements in raw monazite sands by laser-induced breakdown spectroscopy, Optics \& Laser Technology. 43. 45.

[15] Essingt on M. E., Melnichenko G. V., Stewart M. A. and Hull R. A. 2009. Soil Metals Analysis Using Laser-Induced Breakdown Spectroscopy (LIBS). Soil Science Society of America Journal. 73(5). 1469.

[16] Barker AV, Pilbeam DJ. Handbook of Plant Nutrition. 2007, CRC Press.

[17] Ezeh H.N. and Chukwu E. 2011. Small scale mining and heavy metals pollution of agricultural soils. The case of Ishiagu Mining District, South Eastern Nigeria.J. Geol. Mining Res. 3, 87.

[18] Smith S.R. 1994. Effect of soil pH on availability to crops of metals in sewage sludge-treated soils and Cd uptake by crops and implications for human diet ary int ake. Environ.Pollution. 86. 5.

[19] Das P., Samantarary S.and Rout G.R. 1997. Studies on Cadmium Toxicity in Plants: a Review. 